\title{
Supporting students' learning on 'short project' placements
}

\author{
Dr David W. Thompson ${ }^{1}$

\section{D.W.Thompson@wlv.ac.uk}

Institute of Education, University of Wolverhampton, England.

\begin{abstract}
Much of the research into higher education and its role in work-based learning (WBL), and especially in supporting undergraduate students on placements, has focussed on longer term internships and sandwich courses. Research has also focussed on subject areas that have traditionally been associated with the above; for example, Business, Health, and Engineering. By contrast, the aim of this study was to gather data from students on a much shorter period of placement, categorised as a 'short project' (Brennan \& Little, 1996). Furthermore, the data recovered was from students studying within the social sciences paradigm, undertaking an undergraduate degree in Education Studies (not teacher education). The social sciences and humanities more generally have not been discussed to any great extent within the context of research on placement or work-based learning (see Smith, Clegg, Lawrence, \& Todd, 2007); the subject of Education Studies is not covered at all by previous research. This paper considers the different ways practitioners might blend learning and support university students' experiential and academic learning in this short project format. The results suggest that even a relatively short period of structured placement can be of significant benefit to students although for many respondents, face-to-face contact in the form of lectures and tutorials is still an important component of a blended approach to WBL.
\end{abstract}

Keywords: placement, work-based learning, higher education, reflection, blended learning

\section{Introduction}

The aim of this research is to develop a greater understanding of Higher Education (HE) students' placement experiences outside of the more traditional year-long sandwich/internship model. Specifically, the focus is on ways in which students can be supported through a range of support tools and pedagogic practices that help students maximise their placement experience within a credit-bearing module that requires assessments to be passed, and therefore contributes to students' degree classification.

Research and teaching in the United Kingdom relating to work experience and placements in $\mathrm{HE}$ has mainly focused on longer term internships and sandwich courses. In the past, typical subject areas that have encouraged this form of work-based learning (WBL) included Business and Management, Engineering, and Languages. There has been less attention paid to shorter periods of placement at $\mathrm{HE}$ level, as well as a lack of acknowledgement of a much wider range

\footnotetext{
${ }^{1}$ Dr. David Thompson, Senior Lecturer, University of Wolverhampton, Institute of Education, Faculty of Education, Health and Well-being. Walsall Campus, Gorway Road, Walsall, West Midlands, United Kingdom, WS1 3BD. Telephone: 01902322078.
} 
of subject areas; furthermore, it has been suggested that learning on placement is under researched (Murakami, Murray, Sims, \& Chedzey, 2009, p.14).

The locus of this research falls within Brennan and Little's 'Short Project' category in their taxonomy of experience-led work-based learning (1996, p.7). The arts, business, languages, science and engineering are highlighted by the authors; many students in the health professions also undertake placement and field work as an important part of their studies. The social sciences more generally are not represented at all in Brennan and Little's taxonomy and appear to feature relatively little in subsequent research (however, see Smith, Clegg, Lawrence, \& Todd, 2007 for research into Sociology students' experience reflecting on WBL). This paper, therefore, aims to shed light on under-researched aspects of work experience at higher education level by focussing on (i) pedagogies of reflection and blended learning supporting students' experiences within a 'short project' approach to WBL; and (ii) the perspective from an Education Studies undergraduate degree course, a subject positioned within the social sciences paradigm.

\section{Context}

A search through the United Kingdom's Universities and Colleges Admissions Service (UCAS, http://www.ucas.com/) web site revealed around $100 \mathrm{HE}$ institutions offering Education Studies at undergraduate level. This was frequently as a Joint Honours award paired with a National Curriculum subject or another complementary subject such as Childhood Studies, Sociology, or Community and Youth Studies, for example.

Data on the student experience on placement was collected in one post-1992 institution in England. The particular WBL module this research is derived from is credit-bearing and articulates with the institution's Learning and Teaching and Employment strategies. The following were important learning outcomes of the module: developing students' capacity for critical reflection; providing students with opportunities to reflect on a meaningful period of WBL; developing confidence and skills sets for students to take control of their learning and guide their professional development; setting objectives for their placement and reflecting on their performance; and, articulating links between theory, policy and practice. Facilitating these outcomes involved, amongst other things, developing an 'Action Plan' and 'Learning Log'. These provided a structured approach to students' experiential learning and enabled an exploration of the content they studied in lectures and seminars. It also facilitated the application of their theoretical learning to the context of their experience as practitioners. The module design, therefore, reflects Duignan's (2002) recommendation for a 'formal-structure' model of placement, as opposed to a laissez-faire approach.

The module is underpinned with theories of critical reflection (Schon, 1983; Gibbs, 1988; Kolb, 1984 ) that students study and employ as part of their personal and professional development. To achieve the objectives outlined above, a blended approach to learning was designed to help support students in achieving the module's learning outcomes and maximise their WBL experience, especially whilst away from campus and working in their professional setting. There are numerous definitions relating to blended learning; for example, Heinz and Proctor (no date, pp.1-2) allude to a range of definitions such as the effective combination of different modes of delivery, models of teaching and styles of learning and the more simplistic, learning which combines online and face to face approaches. Alternatively, it can be a mode of teaching that eliminates time, place, and situational barriers, whilst enabling high quality interactions between teachers and students... it echoes the practice of distance education (Jeffrey, Milne, Suddaby, \& Higgins, 2014, p.122). The module delivery consisted of traditional lectures, tutorials, learning logs, an 'Action Plan' setting out two objectives for students', online formative activities, the provision of an extensive Handbook with advice and guidance, and additional advice and guidance regularly disseminated through the university's electronic learning platform. Students also received support from the institution's careers department. 
Unlike sandwich courses or courses with block placement, the full time students on this module were expected to continue with their campus-based studies at the same time as undertaking and completing their placement approximately one day per week.

Given that this presented a different approach to the standard lecture format and WBL models, a research project was set up that aimed to collect data on the student experience while undertaking a 'short project' placement and compare it to research conducted nationally and internationally. The aim of the project was to:

(i) Assess the value to students of a 'short project' (Brennan \& Little, 1996) placement;

(ii) Explore the pedagogical framework of the module and the extent to which students felt supported in their experiential learning; and

(iii) Compare findings with published research.

This paper will discuss the second and third aims, focussing on pedagogy and support mechanisms.

\section{Literature}

Placements have been a common feature of undergraduate degree programmes in the UK for more than 40 years (Bennett, Eagle, Mousley, \& Ali-Choudhury, 2008). Reports published in 2001 and 2009 highlight how interest in a variety of WBL opportunities has grown (Wilson, 2009). Furthermore, it is becoming increasingly recognised that WBL in higher education is emerging as a distinct field of practice, supported by relevant pedagogies and concepts of curriculum and that universities are increasingly turning their attention to work experience and graduate employability (Lester \& Costley, 2010, p. 561; HEFCE, 2003). More recently, studies have commented on the importance of work experience; observing that whilst there has been a decline in the practice of placement, short period 'internships' have become increasingly popular (Wilson, 2012, pp.37-39). It is within this context that the research represented in this paper is placed.

\section{Types of WBL}

A number of taxonomies have been developed which help to contextualise the different approaches to WBL. For example, the Wilson review (2012, pp.37-41) discusses the value of sandwich courses, placements, the 'consortium model', 'short period' internships and extracurricular activities. Brennan and Little (1996) outline a spectrum of work-based learning across seven categories from brief encounter to continuing professional development (p.7). Foster and Stephenson (1998) outline different definitions that consider placements, sandwich courses, work experiences, WBL for students, and WBL for employees. Blackwell, Bowes, Harvey, Hesketh and Knight (2001) highlight three main types of work experience within a higher education context: organised, but external to the study programme; ad hoc experience external to the study programme; and organised work experience that is part of the study programme (pp.281-282). The data for this research has been derived from this last category.

\section{The value of $W B L$}

Research into placement experiences can be focussed in a number of different ways. For example, Crebert, Bates, Bell, Patrick, \& Cragnolini (2004) categorise three approaches: the value of the placement to the student, academic staff perceptions of placement, and benefits to students in terms of their careers. Thus at one end of this spectrum students become learners at work with the notion that the placement 'services' the academic course; at the other end the focus is on the needs of employers and employees.

Originally, good practice guides focussed primarily on one-year placements developed over many years (for example sandwich courses), however, it is now widely recognised that work- 
based learning can usefully take place in much shorter time periods (Wilson, J. 2009, p.5; Wilson, T., 2012). Research also suggests that:

spending some months in employment-will usually improve the labour market situation for some of the graduates to some extent. The biggest positive impacts were found to be associated with work done over a longer period (over 8 months) and related to their studies' (Blasko, 2002, p.48, cited in Smith et al., 2007).

The value to students of experiential learning has been highlighted; undergraduates appreciate the opportunity to gain experience and skills in placements that generally have a 'positive effect' on students (Murakami et al., 2009, p.14). In addition, there is significant anecdotal evidence about the efficacy of work experience in general and of embedded work placements in particular (Blackwell et al., 2001, p.270; also see Wilson, 2012). Furthermore, Bennett (2008) asserts that overwhelmingly, investigations have concluded that formal work placements bestow significant benefits on both the students and the firm; advantages include easier transition into employment, a stronger vocational identity and increasing selfconfidence (pp.105-106). Similarly, Pegg and colleagues state there is strong evidence to indicate that authentic work experience contextualises learning, has a strong influence on graduate employment, and should be integrated into course curricula wherever possible (Pegg, Waldock, Hendy-Isaac, \& Lawton, 2012, p.45).

Skills development has also been emphasised in terms of generic key skills of communication, team working and the development of 'social competencies'. Research on placements reinforces a concept of learning as a situated social activity involving development of social skills and management of social relations. Therefore, experiential learning can be empirically observed in the situated development of social competence-the ways of managing and building social relationships in a given context (Murakani, et al., 2009, p.15). Learning as a socially situated activity places a person initially at the peripheral of a 'community of practice' (Lave \& Wenger, 1999); this process of moving from the peripheral towards the centre can also inform our understanding of the student experience in relation to their experiential learning.

WBL has also been critiqued; for example, for the simplistic utilitarianism that currently exists and the instrumentalist and rampant vocationalism where everything is subsumed to work (Hyland, 2001, p.679; also Boden \& Nedeva, 2010). Increasingly, related policies are driven by national governments' neo-liberal agendas, with universities having to respond with a greater emphasis on acknowledging and accrediting work-based learning, developing opportunities to increase the employability of their graduates, and monitoring trends in employment destinations for graduates; resulting in universities losing their independence and autonomy. There has been a growing discourse on the value and appropriateness of employability and WBL at the levels of both policy and practice (Boden \& Nedeva, 2010; Cranmer 2006; Moreau \& Leathwood, 2007). One conclusion is that there are a number of competing agendas relating to WBL; these include employer demands, the race for competitiveness, skills, training at the expense of a universal education, and government policy driven by a perceived need for the UK to compete internationally in order to survive as an economic power (Foster \& Stephenson, 1998, p.156). Furthermore, a caveat is that WBL is potentially limiting if the opportunities provided by the workplace do not form a good match to learners' aspirations, suggesting that work-based programmes can be disempowering visà-vis conventional university learning by trapping the learner into an employer-driven or instrumental agenda (Lester \& Costley, 2010, p.569).

\section{Reflective practice}

The idea that students should engage in reflection on their own practice is not particularly new within $\mathrm{HE}$. It has been advocated by a growing range of theoretical and practical support (Boud \& Walker, 1998; Moon, 2013). Within the teaching and education profession it has become

Thompson, D. (2016). Supporting students' learning on short project placements. Journal of Teaching and Learning for Graduate Employability, 7 (1), 42-57. 
increasingly common to engage in a pedagogy of critical reflection to help underpin experiential learning and continuing professional development (CPD), drawing on, for example, the work of Kolb (1984) and of Schon (1983). There is also a discussion regarding relevant pedagogies that support students on WBL programmes and help them get the most out of their experience. It has been suggested that there are 'pedagogies for employment' (Pegg et al., 2012) with guides for practitioners and for those engaged in policy and practice. Within the context of the field of Education, such approaches can be identified in the work of Pollard (2014), and McGregor and Cartwright (2011) and more generally Moon (2013) and Boud (2005). A pedagogical approach that incorporates elements of reflective practice require students to be active partners in the process and personal development planning is an important element. Pedagogies for employment can be placed within the context of a more general debate about how teaching and learning in $\mathrm{HE}$ is changing, and how it might look in the future. For example, how $\mathrm{HE}$ can become more flexible in meeting the needs of a diverse student body (Ryan \&Tilbury, 2013) and how the move towards on-line learning and students as co-creators of knowledge means there is less of a need for the traditional models of lecture, homework and assessment (Barber, Donnelly, \& Rizvi, 2013).

Pedagogies such as action learning and critical reflection underpin approaches to WBL in other fields, such as the health professions, for example. A corollary is that this moves away from didactic forms of teaching towards facilitation where the 'sage-on-the-stage' is substituted by the 'guide-on-the-side', potentially undermining the traditional role of the academic. Paradoxically, however, it has been noted that lecture-based teaching methods are still important in developing theoretical and abstract contextual knowledge (Pegg et al., 2012, p.32). These different pedagogical stances potentially create tensions and a difficult 'transition' for students and teachers, with the implication that a challenge needs to be met in terms of different styles of delivery, curriculum content, and assessment (Yorke, 2010). Nevertheless, important factors of an effective delivery of WBL include structure and a strong element of reflection (Smith et al., 2007; Pegg et al., 2012). It should also be noted that there are constraints to employing reflective practice; for example, some argue that it is time-consuming, there are too many other important commitments, and emotional barriers (for example facing up to weaknesses and aspects of professional practice that are not going so well, having to relive bad experiences), (McGregor \& Cartwright, 2001, pp187-195). Finlay (2008) highlights a range of 'pedagogic concerns' including that for some students they may not be 'developmentally ready' to engage in reflective practice which can prove counter-productive; furthermore, that where compulsion through assessment of reflective practice is demanded, reflections can be superficial, strategic and guarded (pp.13-15).

Irrespective of the advantages and disadvantages of reflection as a pedagogic practice, the quality of the work experience is important and needs to be an aid to the learning process that also has the potential to be transformative. It is the articulation of what has been learned that is the key (Blackwell et al., 2001). Yorke (2010) emphasises the importance of metacognition to the 'pedagogical landscape' in ways that cover students' self-awareness and their ability to reflect, problem-solve and self-regulate their learning. Further, a case is made to ensure that students undergo a deep learning experience that includes reflection-in-action and reflectionon-action (Smith et al., 2007, p.133). This assists the process of moving from surface to deep approaches to learning; a transformative approach to learning, rather than just working with meaning (Smith et al., 2007, p.134,139). However, these processes are not always evident; The research of Murakani and colleagues (2009) suggests that the placement experience is not always a 'change process' for students: This question of change and learning can pose a difficulty to some, if not all, especially when they were not given a set of criteria to measure change in the individual (p.19).

The points alluded to above apply to taxonomies that classify a range of different approaches to placement and work experience for students in higher education. However, given the nature of shorter placements, it is worth considering to what extent different types of support 
mechanisms and a clear structure is increasingly significant in helping students achieve a meaningful experience on a shorter timescale.

\section{Methodological approach}

An important aspect of the research was to acquire qualitative data that helped understand how students engaged with the module support mechanisms and blended learning approach, designed to support their professional development and maximise their experience whilst on their placement. It was felt that listening to the student voice was especially apposite as students were required to write an assessed piece of work, based upon their experiences.

The standard and generic quantitative format of collecting module feedback had many advantages, but was of limited use for exploring the module-specific student experience in more depth and limited when applied to modules that are more specialised or diverse in their delivery. In order to acquire richer data, a research project was set up with a methodology designed to collect qualitative data on the value of the placement experience to students. The data collection method contained an element of pragmatism that combined quantitative and qualitative data techniques (Flick, 2008).

\section{Data collection}

The research project focused on student perceptions of what was particularly effective in terms of pedagogical approaches and support, outside of the lecture/seminar based delivery traditionally used in higher education. Furthermore, the extent to which students might prefer various forms of learning as part of a blended approach that facilitated tutor-student interaction whilst students were away in placement settings, was also investigated.

A dual approach to data collection allowed both 'structure' (quantitative) and 'process' (qualitative) features (Flick, 2008) to be combined. In terms of structure, questions related mostly to issues surrounding delivery, content, and support in ways that took into account students' responses quantitatively. The process approach related to the student experience in a qualitative way that allowed students' voices to be heard in much more detail, and included a focus group interview. The aim was to invite an honest, personal comment from respondents, the content of which might include 'gems' of information that would not otherwise be collected, (Cohen, Manion, \& Morrison, 2011, p.392). A further aim was to triangulate data sets that provided a snapshot of the feedback surrounding student placements.

Students were asked about how the placement informed their career aspirations, the mechanisms of support whilst in placement and what their preferences were in terms of teaching and learning. Finally, students were asked about the module and general support whilst on placement and what they enjoyed most about their experience.

\section{Questionnaire}

Data was collected through an on-line survey that contained multi-choice questions, Likert scale responses and questions that encouraged open-ended responses in the students' own words; the latter building in a strong qualitative dimension. The online survey was conducted at the end of students' placement. The questions were designed to collect a wide range of information relating to the students' experiences on the module and in their chosen placement. Students were given the opportunity to respond anonymously.

Whilst outlining some quantitative statistics that represent an overview of students' placement experiences, this paper concentrates on an analysis of the open-ended qualitative data in the questionnaire and focus group responses. This enabled a deeper engagement with the feelings and experiences of students during placement. 
To assist triangulation, a focus group interview was undertaken with five students at the end of their placement; the aim was to provide more qualitative and thick description to the data in the questionnaires, to provide a greater orientation to the research and greater coverage (Cohen et al., 2011, p.436). The focus group followed a semi-structured interview design that enabled researchers to discuss key issues uncovered in the questionnaire and in the literature, whilst providing a flexibility that encouraged students to discuss and explore themes that they wished to raise (Denscombe, 2010). Themes included: choice of placement; career pathways; thoughts about the module; and the support it offered and what more could be provided to help support the placement experience. Guiding questions that helped structure the interview related to a discussion on their 'career trajectory' and how their aspirations may have been affected by their placement, a discussion of their feelings about the module and the existing support offered, what they disliked about the module, what further support mechanisms they would like to see and what other changes they would like to make. Finally, students were given the opportunity to raise any other issues that were pertinent to their experience but not covered throughout the rest of the interview. The students' permission was sought, and granted, for the interview to be digitally recorded. The interview was then transcribed.

\section{Data analysis}

An inductive approach to data analysis was taken, moving from a detailed investigation of the specific and particular towards more general conclusions. The data was annotated and coded (Denscombe, 2010) in terms of key words, frequencies of occurrence, and commonalities in the responses, resulting in a number of themes following a familiarisation process with the data. The open coding and axial coding of the qualitative data followed a process comparable to a Grounded approach to collecting data (Strauss \& Corbin, 1997; Glaser \& Strauss, 1967); in particular, accepting the principles that researchers cannot be entirely neutral (Strauss \& Corbin) and researchers need to make sense of the data (Denscombe, 2010). This methodology commonly uses the process of data collection, note taking, coding, constant comparison, and saturation, for example. This process involved developing a set of emerging themes from a range of data following several stages of analysis including; generating natural units of meaning, classifying, categorising and ordering these units of meaning, structuring narratives to describe the contents, interpreting the data (Cohen et al., 2011, p.555). Categories were developed, connections made between them, and the results were compared to their relationship with the literature.

Small qualitative samples clearly have their limitations, especially in terms of extrapolation. However, through a process of constant comparison, the researcher considered a level of saturation (where no new insights are produced) to have been achieved, and therefore this enabled a relatively confident discussion of the implications of the data and how they relate to the theory and practice of placement and WBL.

\section{Data presentation and analysis}

Out of a total of 180 students undertaking the module and going out on placement in one academic year, 51 (28\%) completed the survey and five students agreed to participate in the focus group. The type of placements students participated in reflected the fact that these undergraduate students were studying on education-related courses and expected to be employed within the education sector; however, there was a range of different experiences undertaken. The most popular placement was Primary school (57\%), followed by Early Years $(22 \%)$, then Secondary (7\%); 14 per cent responded as 'other educational organisation' and placements outside the education sector. No-one stated they had a placement in a Further Education college. Students were asked to comment on what 'other' areas of employment they arranged a placement in. This, in fact, revealed an overlap with the previous categories; 
for example, 'sure start centre' (Early Years), 'special school primary' and 'Ofsted' (Office for Standards in Education).

Initially, students were asked which current formats they preferred. All formats (see above) were designed and blended to support students' learning throughout their placement experience. Students were asked to nominate up to three preferences. There were 124 responses; the Action Plan and reflective learning logs (23\% each) being the most popular. Lectures $(20 \%)$ received a similar response. The handbook (13\%) followed in popularity. Emails and on-line support rated relatively low by comparison. These quantitative responses were triangulated with the qualitative open-ended free text comments in the questionnaire, and the focus group interview.

\section{Action plans and learning log}

The results indicate that students valued the structured nature of the approach to learning that helped focus their experience and consider their career options, encapsulated by the Action Plan and learning logs. The Action Plan asked students to consider a skills-based objective and a knowledge-based objective they would like to achieve on placement. It also required students to consider a strategy for meeting those objectives. The positive outcomes of the Action Plan were recognised by the students. Several commented on the focus it provided:

I had a target I knew I aimed to reach.

it helped us focus and helps our future (employability).

I was aware of the things I needed to develop and focus upon.

Others appreciated the opportunity for self-reflection:

Writing a reflective diary (was a particularly useful approach, as was) support with reflective processes.

Allowed self-exploration is the reason why I felt it worked well.

It just prepares you to stand back and view with a deeper understanding.

The opportunity to personalise the goals was also recognised by students who commented:

Being able to develop an action plan enabled me to concentrate particularly on something I was interested in learning about.

Understanding the importance of reflection and being confident and professional (was important to them and their employment chances).

Some of the focus group responses were also pertinent. For example, it was observed that undertaking tasks and a summative assignment meant they had to 'knuckle down' and 'evaluate the whole way through'. As ER commented:

It helped me focus and meet targets I set for myself.

EU was more specific as she reflected on the aims and objectives she was asked to set out in her Action Plan:

I think the fact that we had aims at the start... what we wanted to achieve while we were there... because we had aims and had to write about it I did try... so it was more beneficial... To write an assignment at the end felt I evaluated it more.

$\mathrm{AC}$ added that he felt that the opportunity to link theory to practice was useful:

In the Action Plan you had some theoretical... in your goals... you have to set out theorists... I found on placement I really started to notice things and mentioning things and that started to help the development...had I just gone to add something 
to my CV I probably wouldn't have developed my skills as much...It helped me focus and meet the targets I set for myself.

Reflective practice

Whilst not discussing reflection as a tool in very specific terms, the Focus Group students alluded to the whole process of working to a structured plan that implied they had clearly reflected on their experience. For example, EU said:

For me it was useful in confirming that I didn't want to do primary... it saved me doing P.G.C.E. (Post Graduate Certificate in Education leading to Qualified Teacher Status) and wasting my time ... helped me make my (career) choices earlier.

PB and EU commented respectively:

It has made me stop and think about the teaching profession

It made me think if it's what I want to do (as a career).

The responses outlined above underpin the quantitative data that suggested the Action Plan and reflective pedagogies were important aspects of the blended approach. It was felt that attempting a process of structured reflection helped students to arrive at conclusions regarding to what extent they successfully met their objectives, and if they did not, why? It also helped them to consider routes into professional employment and their strategies for their continuing professional development. As one student put it:

Understanding the importance of reflection (in the education sector) and being confident and professional was important.

However, whilst the quantitative data pointed to theories of reflection as being important in supporting students' development, this was not always borne out in the free-text messages, where a consistent theme was more lectures and tutorials and more research that informs our understanding of this paradox would be welcomed.

Lectures and face to face contact

Students' responses indicated that lectures also played an equally important part in their learning. In fact, the qualitative responses revealed that students still relied upon, or expected, more traditional forms of learning and teaching, even though the main thrust of the placement module was experiential work-based learning. When asked how the module could help further their placement experience, and what aspects of learning and teaching were particularly useful in supporting their placement, a common and consistent theme emerged around the lecture component of this blended approach. For example, there were regular comments asking for more lectures:

Lectures are very useful in supporting me

More contact to keep the ideas fresh

More lectures

Distance learning doesn't help my learning style

More taught sessions

I believe I would have benefited from more contact with lecturers

Having meetings, chats or tutorials with our tutors on a regular basis to discuss placement. 
As one student put it:

I feel more contact with lecturers would have been helpful because you forget... after a while you do not think about the fact that you are doing placement for university.

This theme surfaced consistently, despite the teaching programme on the placement module retaining 65 per cent of the total lectures experienced on traditional campus-based module provision. Some students indicated that they would like to receive visits by lecturers to their placement venue, even though this was not a teacher education programme where their performance had to be assessed in terms of fitness of purpose for teaching.

There were alternative views; for example, one student noted that the learning was:

More personal experience based, so therefore not much teaching was required.

\section{Electronic contact}

Two students commented on the usefulness of regular contact electronically, but generally similar responses were few. In some respects, the data relating to a preference for lecture contact, but also the acknowledgment that experiential learning is core to this module, represents some-what polarised views. Additional research with larger data sets might help shed further light on this issue.

Some students (15\%) also chose practical support mechanisms such as the Placement Handbook and regular contact via Email (12\%) as useful. The Handbook was a forty-two page guide detailing all aspects of the placement experience and advising how students can facilitate and structure their experiences. Typically, Email communication included suggestions for recommended reading, information, advice and guidance on making students' placement more effective, reminders and guidance on formative and summative assignments, information on placement opportunities, and tutorial arrangements.

Given that the core element of this module was work-based learning, researchers wished to explore some of the ways students could be further supported with blended electronic and distance learning. As the main feature of the module was the students' placement experience, it was felt that asking students in what ways they prefer to be supported through electronic mediums was important. Students were asked about a range of electronic support; including simply more Email contact, more on-line activities, social media platforms such as Facebook and Twitter, the development of smart phone apps, generic learning platforms and the on-line messaging and meeting software Skype, students were also asked to suggest other formats they might find helpful.

In some ways the results are paradoxical. For example, students suggested more on-line activities (35\% of responses) and yet the two formative exercises, both on-line, were not popular; furthermore, in an earlier question online support was not a highly rated option. Nevertheless, students indicated they wanted more correspondence via E-mail $(35 \%$ of responses), despite a wealth of alternatives such as the generic on-line learning platform, as well as social media. However, the use of the popular Facebook social media platform was ranked third in terms of support options (13\% of responses) and certainly above other platforms both inside and outside of the institution. In the free text responses, a small number of students referred to more on-line forums and more Email correspondence as ways in which the module could have done more to help, although this type of response was fewer in comparison to more personal contact time through tutorials and lectures. When asked to nominate the most important thing the module could have provided, throughout the 24 freetext responses none referred to additional E-learning or distance learning activities. When asked more specifically about on-line and distance learning there were just seven free-text 
responses. Respondents highlighted Email correspondence, and one person suggested a web page where lecturers are free to talk. In fact, some still stated:

more opportunities for face-to-face tutorials... more lectures (and as one person typically observed)... I would not like any other method of correspondence, I feel we do get a lot of Emails, which is good. Maybe more lectures in general would be beneficial.

\section{Other issues}

Finally, students were given the opportunity to comment in more general terms and raise issues of their own, not guided by the survey questions. Answers were varied, but despite earlier comments on electronic support, by far the most popular response to this question related to the provision of more traditional forms of delivery. More than anything else students commented (at least 10 out of the 26 who responded) that they would prefer either more lectures, smaller group seminars, more discussion with lecturers, more group work and tutor meetings. This coincided with other comments such as more help with assignments and visits by the tutor to the placement location. Only one student commented that the module could have had more on-line delivery.

In conclusion, taking into account qualitative feedback within the questionnaire, quantitative responses, and the focus group interview three key themes emerged. These were that faceto-face contact was by far the most highly valued of all the formats designed to support their experiential learning; students appreciated the existing lectures, the content and support delivered through this format. Secondly, a structured approach to their experiential learning had facilitated their understanding, developed their skills in a planned and measured way, and also seemed to be a motivational tool; it helped students value the placement far more than had it taken a more laissez-faire approach (Duignan, 2002). Thirdly, the underpinning of students' learning with theories of critical reflection was valued as a means of helping students to make sense of their experiences and contextualise their theoretical learning. There was also some evidence to suggest this helped students consider their professional development and their employment trajectory in the future, although further research would help confirm this.

\section{Discussion}

There is a danger that such a short period of experiential learning, in whatever subject discipline, may not achieve its potential value if the placement lacks focus or the duties expected or objectives sought from the experience are not entirely clear. It is the articulation of what has been learned that is the key. That, in turn, depends upon initial purposefulness and then upon regular reflection that involves others. It is enhanced where students are used to thinking metacognitively (Blackwell et al., 2001, p.282). Yorke (2010) supports this position asserting that professional jobs (graduate-level jobs in particular) require the application of metacognition in various ways (p.42) and that this has become a significant feature of the pedagogical landscape... professional jobs require incumbents to apply metacognition and hence a strong case can be made that the teaching approach adopted should foster it (p.7).

In the delivery of the placement module, theories of reflection that were applied together with the Action Plan were pedagogical tools designed to articulate a metacognitive process that helped students move from surface to deeper learning, as well as provide structure and focus to their experiences. This is in line with the findings of Smith and colleagues who comment Moving from surface to deep approaches to learning; a transformative approach to learning, rather than just 'working with meaning'... can result in an 'upgrade' to learning (p.134,139)

'Putting theory into practice' also helped students apply aspects of their theoretical studies in ways that brought important academic topics to life, such as school inclusion, special

Thompson, D. (2016). Supporting students' learning on short project placements. Journal of Teaching and Learning for Graduate Employability, 7 (1), $42-57$. 
education needs, or curriculum delivery, for example. Structuring their experiences with plans, objectives and learning diaries helped provide direction and focus. There was an emerging sense (from the focus group discussions at least) that students started to become 'active partners' in their learning as they began to consider to what extent the objectives they set for themselves had been met, and how their learning informed their ideas about education and their potential career trajectories. It is some-what paradoxical to suggest students were becoming active partners and yet clearly the evidence indicates they preferred more traditional delivery and face-to-face contact with lecturers. Further research on this theme is required, if we are to fully understand the transformation towards being active partners and therefore in turn how institutions support this journey.

Whilst it has been suggested that placement represents a move away from traditional forms of teaching to facilitation, there has been some acknowledgement that Lecture-based teaching methods are still important in developing theoretical and abstract contextual knowledge (Pegg et al., 2012, p.32). Pegg and colleagues (2010) further suggest that the move from traditional didactic teaching methods to facilitation and coaching can be a difficult 'transition' for students; feedback from students in this research appears to corroborate this view. Lecturers may need to carefully 'rethink' their pedagogical approaches, assessments and curriculum (Yorke, 2010). Yorke's (2010) suggestion that a heavy reliance on lectures is anachronistic (p.9) in light of the greater emphasis on virtual learning environments is understandable, as is Ryan and Tilbury's views on flexible and new pedagogies, as is the observation by Barber and colleagues on the importance of developments in on-line learning. However, based on students' responses presented in this paper, there is still some way to go to wean students off traditional forms of provision, if indeed that is what should happen. At the very least, virtual environments need to be developed that will facilitate much more the personal contact aspect, or substitute face-to-face interaction. There were advantages students referred to in the support of their experiential learning that were delivered through a blended approach. Despite this it was clear that many students still regarded contact through the more traditional delivery of lectures and seminars as very important. Generally speaking, students appreciated the existing lectures and the content and support delivered through this format, it was simply that they preferred more of it.

McGregor and Cartwright's (2011) suggestion for a framework for reflection on learning objectives is important within the context of this research (pp.153-154). Whilst the authors apply this to teachers and teacher training, it can also be adapted more generally to the needs of other students and has the potential for wider appeal and application. Evidence from this research indicated that many students were convinced that reflection served as a useful tool to aid their placement experience and ultimately their professional development, as well as feed into their assignment. Furthermore, Moon (2006) discusses the advantages of different structured forms associated with learning journals that help the student move on and go beyond the stage of description (pp.46-47). This helps provide students with a focus to their WBL and develops a deeper and metacognitive approach to learning. It has repeatedly been suggested that the quality of students' reflection is fundamental to the quality of learning. Cowan (1998) has indicated that students may think that they know what skills they have and that they can be wrong. If that is the case, the question is how degree programmes can be designed to help scaffold students to be better at metacognition and at abstracting learning from experience (reflection).

This research confirms that students still value traditional pedagogical approaches. Within the context of a 'short project' placement at least, students regard it as highly beneficial if there is a significant element of face-to-face contact with academic staff, formalised as part of a teaching programme. However, it has been noted (Pegg et al., 2012) that students are active partners in the educational process, and that there is a need to increase their awareness of the wider purpose of each activity in developing their skills, and the value of doing so; practitioners need to help facilitate students to take more responsibility for their experiential 
work-based learning (p.30). Furthermore, it is a difficult transition from didactic approaches to coaching and facilitation, where students again need to take more responsibility for their professional development. Bridges need to be built between different pedagogical models. For example, action learning approaches can be strengthened by reflection and evaluation, but also by integration with more traditional didactic approaches (UKCES, 2008). A balance is important; successful pedagogical approaches include experiential learning - an emphasis on exploration, learning by doing and reflection in authentic contexts - ideally mixed with rather than simply replacing existing approaches (Pegg et al., 2012, p.45). What is pertinent here is the mixing or blending of approaches, rather than simply replacing one with another. Of course it also depends on what, exactly, one means by 'blending'; as we have seen, there are a range of definitions. Fundamental to this is the question of how can we blend in ways that suggest a strong, dynamic, flexible, composite of teaching and learning approaches, rather than a simple mish-mash of learning styles.

The use of action plans and learning logs and the positive reception that students gave these tools reflect Smith's (2007) observation that:

The pedagogical benefits of work-based experiences depend largely on the extent to which students reflect on them and the extent to which they take understandings derived from an academic context and relate these to work-challenges (p.132).

However, as Lucas and Tan (2007) conclude supporting the development of a reflective capacity is not straightforward... it is easy for the best of intentions to be thwarted (p.99).

\section{Conclusion}

The results revealed a wealth of information about students' perceptions of their placement experience and the support they received from campus-based and theoretically-orientated modules. Their standardised feedback could not have revealed such in depth qualitative data. To a large extent the data suggests that students achieved a meaningful and productive experience from a relatively short period of placement.

This research confirmed that students still value traditional approaches to learning and teaching; students regard it as highly beneficial if there is a significant element of face-to-face contact with academic staff, formalised as part of a blended teaching programme designed to support their experiential learning. Furthermore, we have seen from both the literature review and the discussion that students' development of a reflective capacity and the 'transition' away from didactic forms of teaching can be problematic. The data presented and the literature that has been discussed can be viewed as two sides of the same coin; unless we do more to help facilitate blended approaches, then it will be difficult to wean students off the more traditional provision, exemplified by the 'sage-on-the-stage' approach. The highly structured 'Action Plan' and critically reflective 'Learning Log' templates developed for students' placement is at least a start and represents a move towards a more balanced composite of pedagogical approaches.

The short-period placement in this study seemed to benefit students, partly as a result of its structure and focus. It is worth considering that whatever the type of placement a focussed, directed and structured approach to the work experience that is also assessed and creditbearing is not only particularly beneficial to students, but also motivational. This has implications for other settings and subject areas. The structure is helpful in shaping a workbased experience that has clear demonstrable value to students.

More generally, the research concurs with Wilson (2009) who concludes that useful WBL does take place over shorter time periods and can be of significant benefit to higher education students. Whilst Murakani and colleagues (2009) understandably observe that such experiences are not always a change process, the structured objectives and reflective theory underpinning the experience does allow the student to consider to what extent change has

Thompson, D. (2016). Supporting students' learning on short project placements. Journal of Teaching and Learning for Graduate Employability, 7 (1), 42-57. 
happened through a carefully selected set of criteria. Finally, it has been argued that there needs to be clear and associated continuation of this positive, experiential learning into the final year of study (Pegg et al., 2012, p.36). More could be done to articulate this; examples might include how students apply research methodologies or ethical dimensions to the working environment, and how the placement experience could provide an opportunity to undertake some small scale research as part of their final year dissertation project. This would provide clear and strong applied and pragmatic strands right through undergraduates' academic careers, whilst other modules concentrate more on theoretical underpinnings. It is important that the short project placement model is carefully designed to maximise students' experiential learning and metacognitive processes, whilst also getting to grips with some of the problematic concerns of employing reflection already highlighted in this paper. This might offset the heavy reliance of some students on traditional teaching approaches and support, whilst encouraging a pedagogy that enables students to become more confident in becoming active partners in the learning process. 


\section{References}

Barber, K., Donnelly, K., \& Rizvi, S. (2013). An avalanche is coming: Higher Education and the revolution ahead. London: Institute for Public Policy Research.

Bennett, R., Eagle, L., Mousley, W., \& Ali-Choudhury, R. (2008). Reassessing the value of work-experience placements in the context of widening participation in higher education. Journal of Vocational Education and Training, 60(2), 105-122.

Blackwell, A., Bowes, L., Harvey, L., Hesketh, A.J., \& Knight, P.T. (2001). Transforming work experience in Higher Education. British Educational Research Journal, 27(3), 269-285.

Boud, D. (2005). Productive reflection at work: Learning for changing organizations. London: Routledge.

Boud, D., Keogh, R., \& Walker, D. (1998). Promoting reflection in learning: A model. Routledge Falmer: London.

Brennan, J., \& Little, B. (1996). A review of work-based learning in Higher Education. UK: Department for Education and Employment.

Boden, R., \& Nedeva, M. (2010). Employing discourse: Universities and graduate 'employability'. Journal of Education Policy, 25(1), 37-54.

Cohen, L., Manion, L., \& Morrision, K. (2011). Research methods in education. $7^{\text {th }}$ Edition. Routledge: Abingdon.

Cowan, J. (1998). On becoming an innovative university teacher: Reflection in action. Buckingham, UK: Milton Keynes, Open University Press.

Cranmer, S. (2006). Enhancing graduate employability: Best intentions and mixed outcomes. Studies in Higher Education. 31(2), 169-184.

Crebert, G., Bates, M., Bell, B., Patrick, C., \& Cragnolini, V. (2004). Developing generic skills at university, during work placement and in employment: graduates' perceptions. Higher Education Research \& Development, 23(2), 147-165.

Denscombe, M. (2010). The good research guide for small-scale social research projects. Maidenhead: Open University Press.

Duignan, J. (2002). Undergraduate work placement and academic performance: Failing by doing. Canberra: Higher Education Research and Development Society of Australasia.

Finlay, L. (2009). Reflecting on 'Reflective Practice'. Practice-Based Professional Learning Centre. PBPL (52). UK: Open University.

Flick, U. (2008). Designing qualitative research. The Sage Qualitative Research Kit. London: Sage.

Foster, E., \& Stephenson, J. (1998). Work-based learning and universities in the UK: A review of current practice and trends. Higher Education Research and Development, 17(2), 155-170.

Gibbs, G. (1988). Learning by doing: A guide to teaching and learning method. London: Further Education Unit.

Glaser, B., \& Strauss, A.L. (1967). The discovery of grounded theory: Strategies for qualitative research. New York: Aldine Publishing Company.

Heinze, A., \& Proctor, C. (2004). Reflections on the use of blended learning. Salford: University of Salford.

Higher Education Funding Council for England (2003). How much does Higher Education enhance the employability of graduates?

Hyland, T. (2001). Vocationalism, work and the future of Higher Education. Journal of Vocational Education and Training, 53(4,) 677-684. 
Jeffry, L.M., Milne, J., Suddaby, S., \& Higgins, A. (2014). Blended learning: How teachers balance the blend of online and classroom components. Journal of Information Technology, 13, 121-140.

Kolb, D.A. (1984). Experiential learning: Experience as the source of learning and development. London: Englewood Cliffs.

Lave, J., \& Wenger. E. (1999). Situated learning: Legitimate peripheral participation. Cambridge: Cambridge University Press.

Lester, S., \& Costley, C. (2010). Work-based learning at higher education level: Value, practice and critique. Studies in Higher Education. 35(5), 561-575.

Lucas, U., \& Tan, P.L. (2007). Developing a reflective capacity within undergraduate education: The role of work-based placement learning. Report of a research project funded by the Higher Education Academy and the Charitable Trusts of the Institute of Chartered Accountants in England and Wales 2005-07. Higher Education Academy.

McGregor, D., \& Cartwright, L. (2011). Developing reflective practice. A guide for beginning teachers. Maidenhead: Open University Press.

Moon, J.A. (2006). Learning journals: A handbook for reflective practice and professional development. Routledge: Abingdon.

Moon, J.A. (2013). Reflection in learning and professional development. Routledge Falmer: Abingdon.

Moreau, P., \& Leathwood, C. (2007). Graduates' employment and the discourse of employability: a critical analysis. Journal of Education and Work, 19(4), 305-324.

Murakami, K., Murray, L., Sims, D., \& Chedzey, K. (2009). Learning on work placement: The narrative development of social competence. Journal of Adult Development. 16, 13-24.

Pegg, A., Waldock, J., Hendy-Isaac, S., \& Lawton, R. (2012). Pedagogy for employability. UK: Higher Education Academy.

Pollard, A. (2014). Reflective teaching in schools. London: Bloomsbury.

Ryan, A., \& Tilbury, D. (2013). Flexible pedagogies: New pedagogical ideas. York: The Higher Education Academy.

Schon, D. A. (1983). The reflective practitioner: How professionals think in action. London: Temple Smith.

Smith, K., Clegg S., Lawrence, E., \& Todd, M.J. (2007).The challenges of reflection: Students learning from work placements. Innovations in Education and Teaching International, 44(2), 131-141.

Strauss, A.L., \& Corbin, J. (Eds) (1997). Grounded theory in practice. London: Sage.

Universities and Colleges Admissions Service (UCAS, 2010). Retrieved from https://www.ucas.com/

UKCES. UK Commission for Employment and Skills - Employability Skills Project. UKCES (2008). Review of evidence on best practice in teaching and assessing employability skills. Leeds Metropolitan University.

Wilson, J. (2009). A good practice guide and other work-based learning opportunities in Higher Education. Good Practice for Placements Guides. (2). ASET

Wilson. T. (2012). A review of business-university collaboration. Department for Business, Innovation and Skills. Crown Copyright.

Yorke, M (2010). Employability: Aligning the message, the medium and academic values. Journal of Teaching and Learning for Graduate Employability, 1(1), 2-12. 